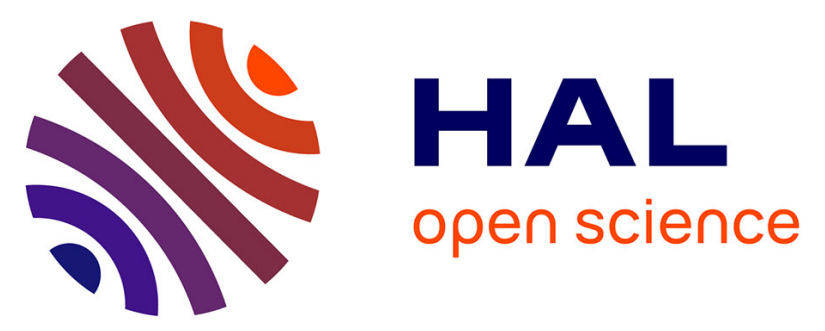

\title{
Combining sclerostin neutralization with tissue engineering: an improved strategy for craniofacial bone repair
}

Sophie Maillard, Ludovic Sicard, Caroline Andrique, Coralie Torrens, Julie Lesieur, Brigitte Baroukh, Thibaud Coradin, Anne Poliard, Lotfi Slimani, Catherine Chaussain

\section{To cite this version:}

Sophie Maillard, Ludovic Sicard, Caroline Andrique, Coralie Torrens, Julie Lesieur, et al.. Combining sclerostin neutralization with tissue engineering: an improved strategy for craniofacial bone repair. Acta Biomaterialia, 2021, 10.1016/j.actbio.2021.11.046 . hal-03466771

\section{HAL Id: hal-03466771 \\ https://hal.sorbonne-universite.fr/hal-03466771}

Submitted on 6 Dec 2021

HAL is a multi-disciplinary open access archive for the deposit and dissemination of scientific research documents, whether they are published or not. The documents may come from teaching and research institutions in France or abroad, or from public or private research centers.
L'archive ouverte pluridisciplinaire HAL, est destinée au dépôt et à la diffusion de documents scientifiques de niveau recherche, publiés ou non, émanant des établissements d'enseignement et de recherche français ou étrangers, des laboratoires publics ou privés. 


\section{Combining sclerostin neutralization with tissue engineering: an improved strategy for craniofacial bone repair}

\section{Running title: Lack of sclerostin boosts bone tissue engineering}

Sophie Maillard ${ }^{1,2}$, Ludovic Sicard ${ }^{1,3 \dagger}$, Caroline Andrique ${ }^{1 \dagger}$, Coralie Torrens ${ }^{1}$, Julie Lesieur ${ }^{1}$, Brigitte Baroukh ${ }^{1}$, Thibaud Coradin ${ }^{4}$, Anne Poliard ${ }^{1}$, Lotfi Slimani ${ }^{1}$, Catherine Chaussain ${ }^{1,3 *}$

${ }^{1}$ Université de Paris, URP2496 Pathologies, Imagerie et Biothérapies Orofaciales et Plateforme Imagerie du Vivant (PIV), FHU-DDS-net, Dental School, Montrouge, France ;

${ }^{2}$ AP-HP Département de parodontologie, Hôpital Rothschild, Université de Paris, France

${ }^{3}$ AP-HP Services de médecine bucco-dentaire, Hôpitaux Universitaires Bretonneau, Charles Foix et Henri Mondor, FHU DDS-net, Ile de France, France

${ }^{4}$ Sorbonne Université, CNRS, Collège de France, Laboratoire de Chimie de la Matière Condensée de Paris, 4 Place Jussieu, 75252, Paris, Cedex 05, France.

$\uparrow$ Contributed equally to this work

*Corresponding author: Catherine Chaussain, URP2496, Université de Paris, 1 rue Maurice Arnoux 92120 Montrouge, France; Tel and Fax: +33(0)158076724; email:

catherine.chaussain@u-paris.fr

Disclosures: none 


\begin{abstract}
Scaffolds associated with different types of mesenchymal stromal stem cells (MSC) are extensively studied for the development of novel therapies for large bone defects. Moreover, monoclonal antibodies have been recently introduced for the treatment of cancer-associated bone loss and other skeletal pathologies. In particular, antibodies against sclerostin, a key player in bone remodeling regulation, have demonstrated a real benefit for treating osteoporosis but their contribution to bone tissue-engineering remains uncharted. Here, we show that combining implantation of dense collagen hydrogels hosting wild-type (WT) murine dental pulp stem cells (mDPSC) with weekly systemic injections of a sclerostin antibody (Scl-Ab) leads to increased bone regeneration within critical size calvarial defects performed in WT mice. Furthermore, we show that bone formation is equivalent in calvarial defects in WT mice implanted with Sost knock-out (KO) mDPSC and in Sost KO mice, suggesting that the implantation of sclerostin-deficient MSC similarly promotes new bone formation than complete sclerostin deficiency. Altogether, our data demonstrate that an antibody-based therapy can potentialize tissue-engineering strategies for large craniofacial bone defects and urges the need to conduct research for antibody-enabled local inhibition of sclerostin.
\end{abstract}

Keywords: Dental pulp stem cells, Sost/sclerostin, Tissue engineering, bone repair, dense collagen hydrogel, monoclonal antibody therapy 


\section{Introduction}

High bone mass diseases, namely Sclerosteosis and Van Buchem disease, are due to loss-offunction mutations of the SOST gene, which encodes sclerostin, a glycoprotein involved in the canonical Wnt (wingless-related integration site)/ $\beta$-catenin signaling pathway. Sclerostin, secreted primarily by osteocytes, has been shown to be a potent inhibitor of bone formation through the inhibition of the canonical Wnt signaling pathway. This pathway is activated following binding of one of the Wnt proteins and downregulated after interaction with sclerostin $[1,2]$ and the LRP (low-density lipo-protein receptor-related protein) $5 / 6$ receptor [3-6]. Accumulating evidence revealed that this paracrine interaction controls cell behavior, tissue formation and bone modeling/remodeling. These observations led to extensive preclinical investigations [7-13], and to the development of several neutralizing antibodies raised against sclerostin. Their evaluation in several randomized clinical trials conducted in women with osteoporosis (romosozumab and blosozumab) [14-18], or in patients with osteogenesis imperfecta (setrusumab-BPS-804) [19, 20], showed that the systemic delivery of sclerostin antibodies significantly increased bone mass density through promoting osteoblast differentiation while inhibiting osteoclast formation [6, 21, 22]. Sclerostin neutralization was also shown to improve bone healing of fracture or critical-sized femoral defect in normal and pathological rodent models [23-30]. Furthermore, a tissue engineering approach based on the delivery of a miRNA targeting sclerostin was evaluated in a canine mandibular defect with positive outcomes on bone repair [31]. However, this latter approach remained isolated and no other tissue engineering strategy associated with sclerostin inhibition has been reported for bone regeneration so far.

During the last decade, mesenchymal/ stromal stem cells (MSC) have been of substantial interest to both clinicians and researchers for their considerable enhanced tissue regenerative 
potential [32]. Indeed, their accessibility, genomic stability, high expansion in vitro, potential for differentiation and ethical acceptability make them good stem cell candidates for tissue engineering. In particular, MSC derived from the dental pulp are considered as an attractive cell source for craniofacial bone regeneration due to their classical MSC properties, their easy access, the less invasive approach to harvest [33-35], their identical embryologic origin [36, 37] and their high capacity for proliferation and differentiation into bone secreting cells [38]. Recent studies have shown the potential of dental pulp stem cells (DPSC) to form bone in mouse models of craniofacial bone defects, indicating that DPSC were very suitable candidates for the enrichment of craniofacial bone substitute [39-44]. Along this line, we previously reported that murine dental pulp stem cells (mDPSC) harvested from tooth germ of Sost knockout $(\mathrm{KO})$ mice and therefore lacking sclerostin expression exhibited a higher mineralization capacity compared to their WT counterparts when exposed to mineralizing culture conditions [10].

A large variety of biomaterials has been used as cell hosts for bone tissue engineering approaches [45], including hydrogels based on natural polymers such as type I collagen [4650]. To compensate the inherent lack of structural consistence of common collagen hydrogel, a "plastic compression" has been proposed to increase the relative fibrillar density [51-54], resulting in a density similar to the osteoid tissue [55-58]. Supporting the interest of this approach, our team has established the osteogenic potential of DPSC-seeded dense collagen hydrogels implanted in rodent calvarial defects [39, 43, 44]. A strategy aiming at further enhancing bone regeneration in terms of volume and quality within such constructs would constitute a major therapeutic advance. In particular, recent advances in the association of immunotherapy and biomaterials in the field of cancer treatment [59-61] suggest that combination of such scaffolds with a neutralizing sclerostin antibody may constitute a highly promising approach. Therefore, in the present study, we aimed at assessing whether the 
neutralization of sclerostin may improve the efficacy of a tissue engineering strategy for treating large craniofacial bone defects. In that purpose, we evaluated whether bone formation was enhanced in parietal defects performed in wild-type (WT) mice weekly treated with a systemic injection of a sclerostin antibody ( $\mathrm{Scl}-\mathrm{Ab})$ during the bone regeneration process. In parallel, WT mice were restored with dense collagen hydrogels enclosing Sost KO mDPSC and compared to WT mice similarly treated with WT mDPSC. Our results show increased bone formation in WT mice either under systemic pharmacological sclerostin neutralization or implanted with Sost KO mDPSC. These observations strongly support the interest of combining a tissue engineering strategy with sclerostin neutralization for the treatment of large craniofacial bone defects, either through systemic injection or by local delivery.

\section{Materials and methods}

\subsection{Study design}

Two independent experiments have been designed in order to assess the interest of sclerostin deficiency in bone regeneration. In the first experiment, a $3.5 \mathrm{~mm}$ critical size defect was surgically created in the parietal bone in 10-week-old male Sost KO mice (n = 40) and wildtype mice $(n=40)$. The defects were subject to the following conditions: (i) either left empty (no collagen-hydrogel), filled, ii) with an acellular collagen-hydrogel, or with a collagenhydrogel seeded with mDPSC, iii) from WT mice (WT mDPSC) or iv) Sost KO mice (Sost KO mDPSC).

In the second experiment, male WT mice were randomly assigned to Scl-AB (Setrusumab, BPS804; kind gift from Mereo Biopharma (London, UK) ( $n=10$ per group) or vehicle (saline solution) injection, ( $\mathrm{n}=10$ per group), according to Roschger et al [62]. In brief, Scl-AB was injected intravenously at a dose of $100 \mathrm{mg}$ per $\mathrm{kg}$ body weight. Injections of Scl-AB or the vehicle were given once a week over a period of eight weeks. Mice were euthanized at the end 
of the eight-week intervention period, i.e., at the age of 18 weeks. Body weights were recorded at the time of each injection.

\subsection{Ethical approval and animal management}

All experiments in this study were conformed to ARRIVE (Animal Research: Reporting of in vivo Experiments) guidelines and were approved by the Animal Care Committee of the Université de Paris (APAFIS agreement \# 24297 N²019022017023656). Animals were maintained according to the guidelines for ethical conduct developed by the European Communities Council Directive (animal breeding agreement C92-049-01). All efforts were made to minimize their pain or discomfort. Hundred forty ten-week-old male mice (100 WT and 40 Sost KO) with a C57BL/6J genetic background were used for this study[10] and were housed in stable conditions $\left(22 \pm 2^{\circ} \mathrm{C}\right)$ with a $12 \mathrm{~h}$ dark/light cycle and with ad libitum access to water and food.

\subsection{Isolation and culture of Dental Pulp Stem Cells from PN3 WT or Sost KO mice}

Multi-colony-derived mouse dental pulp stem cells were obtained from the molars of three-day postnatal (PN3) littermate Sost KO mice and WT mice using a protocol adapted from [36],[10]. Briefly, murine molar gems were collected under sterile conditions and incubated at $4{ }^{\circ} \mathrm{C}$ for $45 \mathrm{~min}$ in phosphate-buffered saline (PBS) containing $100 \mathrm{U} / \mathrm{ml}$ penicillin/streptomycin (Gibco, Hampton, USA) and $250 \mu \mathrm{g} / \mathrm{ml}$ fungizone (Gibco), then in PBS containing three $\mathrm{mg} / \mathrm{ml}$ type I collagenase (Worthington Biochem, Freehold, NJ, USA) and two U/ml dispase I (Roche, Mannheim, Germany) in a shaking incubator (at $37^{\circ} \mathrm{C}$ ) for one hour. The isolated cells were then plated on $0.1 \%$ gelatin-coated dishes in the Minimum Essential Media-alpha (Gibco) supplemented with $20 \%$ v/v fetal bovine serum (FBS) (Gibco) and $100 \mathrm{U} / \mathrm{ml}$ Penicillin/streptomycin (Gibco), $2.5 \mathrm{ng} / \mathrm{ml}$ FGF-2 (PeproTech, Neuilly-Sur-Seine France), $10 \mathrm{ng} / \mathrm{ml}$ BMP-2 (PeproTech), and maintained at $37{ }^{\circ} \mathrm{C}$ under $5 \% \mathrm{CO}_{2}$ atmosphere. The 
medium was changed after two days, and then twice a week. The required cell number for in vivo experiments was reached after two to three passages.

\subsection{Collagen-hydrogel preparation}

Plastically compressed collagen gels were used as three dimensional scaffolds and prepared as previously described $[52,63,64]$. Briefly, $3.2 \mathrm{ml}$ of sterile rat-tail collagen type I (First Link Ltd., Wolverhampton, U.K.) at a protein concentration of $2.0 \mathrm{mg} / \mathrm{ml}$ in $0.1 \%$ acetic acid was mixed with $0.4 \mathrm{ml}$ of 10X Dulbecco's Modified Eagle Medium (DMEM) and neutralized by $0.4 \mathrm{ml} 10 \mathrm{X} \mathrm{HCO}^{3-}$ and drop-wise addition of $0.1 \mathrm{~N} \mathrm{NaOH}$ to $\mathrm{pH} 7.4$ [65]. After neutralization, acellular or with mDPSC at a seeding density of $2.10^{6} \mathrm{cell} / \mathrm{ml}$ was ice-cold mixed and 0.9 $\mathrm{ml} /$ well of the mix was platted into a four-well plate. After gelling $\left(30 \mathrm{~min}\right.$ at $\left.37^{\circ} \mathrm{C}\right)$, highly hydrated hydrogels were placed on a stack of blotting paper, nylon, and stainless steel meshes. Dense collagen hydrogels were produced by the application of an unconfined compressive stress of one $\mathrm{kPa}$ for five min to remove excess casting fluid. The compressed scaffolds were circularly cut (four mm diameter) and kept up to $24 \mathrm{~h}$ at $37{ }^{\circ} \mathrm{C}$ under $5 \% \mathrm{CO}_{2}$ in serum-free medium before implantation [66].

\subsection{Surgical implantation}

Mice were anesthetized (100 mg/kg b.w. of ketamine and $10 \mathrm{mg} / \mathrm{kg} \mathrm{b.w.} \mathrm{of} \mathrm{xylazine}$ hydrochloride, both from Centravet Alfort, Maisons-Alfort, France). In each specimen, scalp skin was incised, and the periosteum was eliminated to visualize the skull. A $3.5 \mathrm{~mm}$ diameter calvarial critical-sized defect was created on each side of the parietal bone using a dental bur attached to a slow-speed hand piece operating at $1500 \mathrm{rpm}$, under irrigation with sterile saline solution [67]. Special care was taken for the sagittal suture preservation, and minimal invasion of the dura mater. After gently removing the circular bone plug, a mDPSC-seeded dense collagen-hydrogel or acellular dense collagen-hydrogel prepared as previously described was 
implanted in bone defect $\left(n=280\right.$ hydrogels for the entire experiment $\left(\mathrm{n}^{\circ} 1\right.$ and 2$)$ : acellular hydrogel, hydrogel seeded with WT mDPSC or hydrogel seeded with Sost KO mDPSC. Each animal was randomly allocated per cage and per group and received the same treatment on both sides. Wound closure was achieved by a suturing (periosteum, skin) using absorbable sutures (Vicryl Rapid 5.0 and 4.0 respectively, Ethicon, Johnson \& Johnson). Immediate postoperative care included analgesia with buprenorphine (0.02 mg/kg b.w.). After surgery, the animals were housed individually under constant conditions. No lethality was detected during the surgery or the post-operative period. Wound healing progressed without any sign of infection, material exposure or other complication. Body weights were examined regularly to ensure proper feeding before and after surgery.

\subsection{Micro-X-ray computed tomography (Micro-CT) examination of samples.}

For bone regeneration exploration, mice were anesthetized (isoflurane, induction at $2-2.5 \%$ under airflow of $0.8-1.5 \mathrm{~L} / \mathrm{min} ; 1-1.5 \%$ under $400-800 \mathrm{ml} / \mathrm{min}$ thereafter) and were imaged using an X-ray micro-CT device (Quantum FX Caliper, Life Sciences, Perkin Elmer, Waltham, MA) hosted by the PIV Platform, URP2496, Montrouge, France. The X-ray source was set at $90 \mathrm{kV}$ for the voltage and $160 \mu \mathrm{A}$ for the intensity. Tridimensional images were acquired with an isotropic voxel size of $20 \mu \mathrm{m}$. Full three dimensional high-resolution raw data are obtained by rotating both the X-ray source and the flat panel detector $360^{\circ}$ around the sample (scanning time: 3 min). Tridimensional rendering was subsequently extracted from DICOM image stacks using the open-source OsiriX imaging software (v5.7.1, distributed under LGPL license, Dr A. Rosset, Geneva, Switzerland) [68]. Before quantification, image stacks were reoriented using DataViewer (Skyscan, release 1.5.2.4, Kontich, Belgium) to the center of the defect. Then, quantification of the regenerated bone was performed with a cylindrical shape volume of interest of $3.5 \mathrm{~mm}$ of diameter and $1 \mathrm{~mm}$ height, using CT-Analyzer software (Skyscan, release 1.13.5.1, Kontich, Belgium). An adaptative thresholding was performed with a radius of two, 
between 364.34 and $560.82 \mathrm{mgHA} / \mathrm{cm}^{3}$ (HA: Hydoxyapatite). To reduce background, open/close morphological operations (radius $=1$ ) were performed on the segmented bone. Bone volume fraction BV/TV (BV: Bone volume and TV: Total volume) (\%), porosity (mm ${ }^{3}$ ) and Bone Mineral Density (BMD, $\mathrm{mgHA} / \mathrm{cm}^{3}$ ) were used to quantify and characterized newly repaired bone. Since the regenerated bone is mainly a compact bone, trabecular thickness Tb.Th (mm), trabecular number Tb.N (one per $\mathrm{mm}$ ) and trabecular separation Tb.Sp (mm) were not described due to the fact that these values are specific to trabecular bone [69].

\subsection{Histology, histomorphometry}

Two-months non-decalcified samples ( $\mathrm{n}=6$ defects per condition) were fixed in $70 \% \mathrm{vol} / \mathrm{vol}$ ethanol $\left(24\right.$ hours at $\left.4^{\circ} \mathrm{C}\right)$, dehydrated in graded ethanol solutions and embedded at $-20^{\circ} \mathrm{C}$ in methacrylate resin (Merck \& Co., Whitehouse Station, NY) [70]. Five- $\mu$ m thick deplastified calvaria bone sample sections were sequentially cleared in water and stained with von Kossa staining, or processed for alkaline phosphatase (ALP) enzyme-histochemistry and for tartrateresistant acid phosphatase (TRAP) revelation [43]. Von kossa staining was used to visualize mineralized bone. TRAP was detected by using hexazotized pararosanilin (Sigma) and naphtol ASTR phosphate (Sigma, St Louis, MO) to reveal osteoclasts; non-osteoclastic acid phosphatase was inhibited by adding $100 \mathrm{mMol} / \mathrm{L} \mathrm{L(+)-tartric} \mathrm{acid} \mathrm{(Sigma,} \mathrm{St} \mathrm{Louis,} \mathrm{MO)} \mathrm{to}$ the substrate solution.

\subsection{Image acquisition and quantification}

Image acquisition was performed using a Lamina multilabel slide scanner (Perkin Elmer) hosted by the HistIM platform at the Institut Cochin, Paris. Slide visualization was performed with CaseViewer, 3DHISTECH's advanced slide viewing software, and images were analyzed using Fiji (Fiji Is Just ImageJ) [71], an open source image processing package based on ImageJ ( 


\subsection{Second harmonic Generation (SHG) Microscopy}

Second harmonic generation microscopy offers the opportunity to image and quantify collagen without staining, and was used as previously described [72]. Briefly, a multiphoton inverted stand Leica SP5 microscope (Leica Microsystems GmbH, Wetzlar, Germany) hosted in the IMAG'IC facility at the Institut Cochin, Paris, was used for calvaria imaging. A Ti:Sapphire Chameleon Ultra (Coherent, Saclay, France) with a center wavelength at $810 \mathrm{~nm}$ was used as the laser source for generating second harmonic (SHG) and two-photon-excited fluorescence (TPEF) signals. The laser beam was circularly polarized. A Leica Microsystems HCX IRAPO $25 \times / 0.95 \mathrm{~W}$ objective was used to excite and collect SHG and TPEF signals.

Signals were detected in epi-collection through $405 / 15 \mathrm{~nm}$ and $525 / 50$ bandpass filters, respectively, by NDD PMT detectors (Leica Microsystems) with a constant voltage supply, at constant laser excitation power, allowing the direct comparison of SHG intensity values. LAS software (Leica, Germany) was used for laser scanning control and image acquisition. Analyses were performed using a homemade ImageJ routine. Two fixed thresholds were chosen to distinguish biological material from the background signal (TPEF images) and specific collagen fibers. The SHG score was established by comparing the area occupied by the collagen relative to the sample surface.

\subsection{Statistical analysis}

Numerical variables are expressed as the mean \pm standard error of the mean (S.E.M). The statistical analyses were performed using Prism software version 7.04 (GraphPad software, La Jolla, CA). The normality of the distribution was tested with the D'Agostino-Pearson omnibus normality test and the homogeneity of variance was tested with the Fisher F test. Since data was following a normal distribution and variances were significantly different between groups, a Brown-Forsythe and Welch ANOVA parametric test allowing the comparison between more than two independent samples was performed. As two defects were performed for each animal, 
it was the bone defect that was considered as the statistical unit. Differences were considered significant at $\mathrm{P}<0.05$.

\section{Results}

\subsection{The implantation of Sost KO mDPSC in WT mice potentiates the outcomes of a tissue engineering strategy}

To assess the interest of the inhibition of sclerostin for a tissue engineering approach, we first investigated bone formation in calvarial defects performed in WT mice and implanted with hydrogels enclosing Sost KO mDPSC, in comparison to WT mice implanted with hydrogels enclosing WT mDPSC (Fig.1,2). The MSC nature of these cells has been previously established $[44,73]$. Sost $\mathrm{KO}$ mice, which have been shown to display a strong bone formation potential $[11,74]$, were treated similarly as a positive control. For each genotype, four different conditions were applied i) defect left empty (no hydrogel), ii) defect filled with a dense acellular collagen hydrogel, iii) defect filled with a dense collagen hydrogel enriched with WT mDPSC, and iv) defect filled with a dense collagen hydrogel enriched with Sost KO mDPSC. Bone healing was analyzed by micro-CT at two months (Fig.1a) and further characterized by histology. Micro-CT analyses indicated that neither WT nor Sost KO parietal defects left empty experienced bone repair at the center of the defects, confirming the critical size defect nature of our model even in Sost KO animals (Fig.1a). For all the other conditions, bone formation was observed at both the edge and the center of the defects. As expected [11, 74], increased BV/TV was systemically found in Sost KO mice when compared to their WT counterparts and the addition of mDPSC, either WT or $\mathrm{KO}$, did not improve bone formation in $\mathrm{KO}$ animals (Fig.1a). In contrast, in WT mice, the addition of mDPSC significantly improved bone formation compared to acellular hydrogels. Furthermore, WT mice treated with Sost KO mDPSC-seeded hydrogels displayed a significantly higher BV/TV compared to WT mice that 
received WT cells $(\mathrm{P}<0.0001)$. The BV/TV measured in WT mice treated with Sost KO cells was not significantly lower than those obtained in the positive control (Sost KO mice).

Both ALP, which reflects osteoblast activity, and von Kossa staining, which shows mineral formation, were robust in Sost KO mice and in WT mice treated with Sost KO mDPSC (Fig.1b; c). Quantification of Von Kossa staining confirmed these observations. Consistent with our micro-CT findings, WT mice treated with Sost KO cells showed a significantly higher percentage of mineralized tissue in the defects compared to WT mice treated with WT cells (Fig.1b; $\mathrm{P}<0.001$ ). Of note, in Sost $\mathrm{KO}$ mice, the addition of $\mathrm{KO}$ cells significantly improved mineral deposition when compared to the addition of WT cells. We then explored osteoclast resorption activity within the defects by assessing TRAP activity (Fig. 2a). No significant difference was found for either WT or Sost KO mice treated with WT or KO cells, indicating that, in our model, Sost deletion favors bone formation but does not influence resorption (Fig.2a). We next investigated the newly formed bone using second harmonic generation (SHG) microscopy (Fig. 2b). Red-labeled well-organized bundles of collagen fibers were observed within the defects performed in WT and Sost KO mice treated with either WT or KO cells, indicating that the addition of mDPSC within the hydrogels favors matrix reorganization. However, analysis of the bone porosity and density from micro-CT acquisitions showed no benefit for the addition of mDPSC in the hydrogel either in WT or Sost KO mice, indicating that even if more bone is formed in KO mice and in WT mice treated with KO cells, these microarchitecture parameters are not improved at this stage of the repair process by the Sost deletion (Fig. 2c).

Taken together, these data showed increased bone formation in WT animals implanted with Sost KO mDPSC at two months. The deletion of Sost in the implanted cells displayed a similar potential to stimulate bone formation than Sost KO animals treated with WT or KO cells. 


\subsection{Systemic Scl-Ab treatment potentiates the outcomes of tissue engineering strategy in}

\section{WT mice}

Based on our data showing improved bone repair in the defects performed in WT mice treated with Sost KO mDPSC, we sought to investigate whether the administration of a sclerostinneutralizing Scl-Ab $[19,20]$ to WT mice may improve a tissue engineering strategy (dense collagen hydrogels enriched with mDPSC). To this end, the bone repair process within calvarial defects, either empty or filled with acellular or WT mDPSC cellularized hydrogels, was analyzed after two months in WT mice weekly injected with Scl-Ab or vehicle (Fig.3,4). Representative three dimensional images of bone defects created in WT and Sost KO mice in four conditions (Fig.3a) revealed a complete closure of the defect in mice treated with the Scl $\mathrm{Ab}$ and a hydrogel enclosing mDPSC, and an almost complete one for the acellular hydrogels (Fig.3a). The quantitative analysis highlights that the BV/TV was significantly higher in the $\mathrm{Scl} \mathrm{Ab}$-treated animals compared to the vehicle injection (Fig.3a). Noteworthy, in these Scl $\mathrm{Ab}$-treated animals, the addition of mDPSC in the hydrogel significantly improved bone repair when compared to acellular controls $(\mathrm{P}<0.0001)$. Accordingly, ALP staining indicated a strong osteoblast activity in this condition (WT mDPSC combined with Scl-Ab) (Fig.3b), and Von Kossa staining revealed a significantly higher amount of mineralized tissue formation with $\mathrm{Scl}-\mathrm{Ab}$ injection than in vehicle-only controls (Fig.3c). Furthermore, in these Scl Ab -treated animals, the addition of WT mDPSC further improved mineralization when compared with the "acellular hydrogel" condition $(\mathrm{P}<0.01)$ (Fig. 3c). In contrast, no difference regarding osteoclast activity was found in this group, suggesting that the antibody rather targets bone formation than bone resorption at the stage of the process (Fig. 4a).

Next, we investigated the quality of the newly formed bone using SHG microscopy (Fig. 4b). This analysis indicated better collagen fiber organization in mice treated with the Scl-Ab when compared to the vehicle for all the conditions, but this observation was particularly striking for 
cellularized defects. Analysis of the bone porosity and density from micro-CT acquisitions showed a significantly lower porosity in defects performed in animals treated with the Scl-Ab compared to vehicle (Fig.4c). However, at this stage of the bone repair process, the addition of cells did not impact these microarchitecture parameters. Taken together, these data show higher bone formation with upregulation of the osteoblastic activity within the calvarial defects in cellularized tissue engineered constructs associated with Scl-Ab injection.

\section{Discussion}

Tissue engineering appears as a promising option to treat large bone defects [45], especially in the context of the craniofacial area, which requires extremely difficult surgical reconstructions. Here, we have raised the hypothesis that a tissue engineering strategy, namely implantation of dense collagen hydrogels enclosing mDPSC, combined with the inhibition of sclerostin may greatly enhance bone regeneration within critical size calvarial defects. Our data show that sclerostin neutralization by the systemic injection of a sclerostin antibody [19, 20], a strategy already used to treat osteoporosis and other bone diseases $[6,21,75,76]$, markedly improves the outcomes of our tissue engineering approach, resulting in higher bone formation in animals treated with both Scl-Ab and hydrogels, and especially with those enriched with mDPSC.

The use of the dental pulp as source of MSC appears fully justified here as most of the craniofacial bones and the dental pulp MSC share a common neural crest embryological origin $[37,77]$. In addition, neural-crest derived osteogenic cells are known to be more efficient in osteoblast differentiation and bone repair than their mesoderm counterparts [78]. Regarding the use of dense collagen hydrogels as a scaffold, we and others have previously demonstrated that such scaffolds allowed the addition of MSC and a fiber density favoring osteogenesis, while being perfectly tolerated by the host upon implantation $[39,44,52,55,56,58,79]$. In our study, the addition of DPSC within the dense collagen hydrogels markedly improved bone 
regeneration in WT mice, which is consistent with previous studies in rodent models $[39,43$, $44,56,73]$. This observation is true for our two sets of experiments despite the fact that the amount of newly formed bone differed between these experiments. This may be due to the fact that these experiments were conducted independently, at different time of the year and with different batches of cells and reagents.

The benefit of mDPSC addition was less marked in Sost $\mathrm{KO}$ mice, as bone formation was comparable in acellular hydrogels and hydrogels enriched with mDPSC harvested from WT or KO molar germs (Fig. 1a). This suggests that permanent sclerostin deficiency in these animals overcomes the potential of these MSC to improve bone healing. In 2011, a study reported that osteoblasts harvested whether from juvenile or adult mouse parietal bones demonstrated reduced capacity for osteogenic differentiation when exposed to recombinant sclerostin, already pointing out this protein as a promising target to abrogate in future tissue engineering studies [80]. As expected, calvarial defects performed in Sost KO mice healed faster and better that those performed in WT mice (Fig. 1a and Fig. 2b). These findings are consistent with other studies conducted in the Sost KO mouse model or other mouse models targeting another inhibitor of the Wnt/ $\beta$-catenin signaling pathway such as DKK1 (Dickkopf 1). In these studies, higher bone formation was reported in the transgenic models compared with their WT counterparts $[11,74,81-83]$. Regarding the high bone formation potential associated with sclerostin deficiency, a complete healing of the bone defects left empty (no hydrogel) may have been expected, in view of the reported finding that Sost $\mathrm{KO}$ mice were able to regenerate up to $40 \%$ of the calvarial defect two months after surgery [81]. However, in this case, bone formation was only observed at the edge of the defects and in a limited number of mice. In our hands, defects left empty in Sost KO mice, as well as in WT mice treated with the Scl-Ab, displayed very limited bone formation (Fig. 1a). 
Quite remarkably, our data show that WT mice treated with mDPSC harvested from Sost KO molar germs displayed a bone healing process significantly improved compared with WT mice treated with WT cells (Fig. 1a-c). The bone quantity in these animals was comparable to their Sost KO counterparts (Fig. 2 b). These important findings suggest that the local absence of sclerostin in the MSC implanted in a bone defect has an equivalent benefit in terms of bone regeneration to its complete deficiency. This is consistent with a previous study showing that the local delivery of small active fragments of the sclerostin antibody loaded in Poly(lactideco-glycolide) microspheres and implanted within the fracture site favored bone healing in ovariectomized (OVX) rats [84]. Noteworthy, Phase III clinical trials conducted in patients with osteoporosis have shown that the systemic neutralization of sclerostin with a monoclonal antibody was not devoid of adverse events, albeit very rare, such as osteoarthritis, arthralgia, nasopharyngitis or back pain as well as an increased incidence of cardiovascular events [85, 86]. These studies have also unraveled a possible effect on the occurrence of osteonecrosis of the jaw (ONJ). This later adverse event, albeit extremely rare (two cases reported in the FRAME clinical trial) [87], is of particular importance in our prospect to develop a tissue engineering strategy for the craniofacial skeleton. Quite reassuring, a recent study conducted in OVX rats, in which experimental periodontitis was induced through ligature placement and which were treated by either a sclerostin antibody or bisphosphonate, did not develop ONJ under anti-sclerostin treatment while showing improved maxillary bone healing when compared to animals treated with bisphosphonate [88]. However, the positive outcomes of our present experiments conducted in WT mice treated with Sost KO mDPSC together with those previously obtained with the local and controlled delivery of active fragments of a sclerostin antibody [84], suggest that the local inhibition of sclerostin in a defect may be sufficient to improve bone healing, while limiting the potential adverse events associated with a systemic treatment. 
Both clinical and preclinical studies have demonstrated that the major effect of the systemic administration of a sclerostin antibody was the uncoupling of bone remodeling, leading to an increase in bone formation [21, 89-92], and a decrease in bone resorption with lower osteoclastic activity [93]. Here, we observed robust osteoblast activity evidenced by ALP staining whenever sclerostin was deficient (Fig. 1b) or neutralized (Fig. 3b), coupled with no impact on osteoclast activity in the defects (Fig. 2a and Fig. 4a). Furthermore, we found that the porosity of the regenerated bone was improved by the antibody treatment compared to the placebo but not by the addition of the MSC in the dense collagen hydrogels with sclerostin deficiency (Fig. 2c) or neutralization (Fig. 4c). This micro-architecture parameter, which is commonly used for the characterization of the cortical bone, is considered, when increased, as a robust marker of bone fragility that might help to identify patients with increased risk of fracture [94]. Therefore, together with our SHG observations showing improved organization of the collagen fibers when sclerostin is inhibited or absent, we can conclude that sclerostin deficiency or neutralization improved the quantity and the extracellular matrix organization of the regenerated bone. However, this newly formed bone still needs to be further remodeled to decrease its porosity and increase its density. Yet, our experiments were conducted in the calvaria, which is a flat bone exposed to limited (although not negligible) mechanical constraints [95]. These limited mechanical constraints may explain the lack of maturity observed in the regenerated bone, even in Sost KO animals. Hence, we selected the calvarial bone defect in first instance, as it is a critical and highly reproducible model [96]. In the future, our tissue engineering approach combined with Scl-Ab should be explored in a more mechanically solicited bone such as the mandible, either in rats or in larger animal models.

\section{Conclusions}


In conclusion, the sum of our work highlights that sclerostin neutralization by a monoclonal antibody improved bone healing in a tissue engineering strategy for the craniofacial area. Furthermore, similar outcome was observed with the implantation of MSC deficient for sclerostin directly within the bone defect, suggesting that the local absence of this protein during the bone healing process should be a therapeutic strategy to investigate, for instance via the controlled delivery of the antibody from the tissue engineering construct. Beyond sclerostin, monoclonal antibodies targeting other regulators of the bone remodeling process, such as the RANK/RANKL pathway, are available and may be promising candidates to explore further the potential of a combined therapeutic monoclonal antibody-tissue engineering strategy for bone regeneration.

\section{Acknowledgements}

Experiments were supported by grants from Fondation des Gueules Cassées to URP2496. Micro-CT device was funded by Fondation pour la Recherche Médicale for Plateforme d'imagerie du Vivant Université de Paris and URP2496 (FRM DGE20111123012). SM PhD was supported by Fondation des Gueules Cassées. Authors thank Jeremy Sadoine (URP2496 and PIV, Université de Paris, France) for his assistance and expertise regarding micro-CT acquisitions and analyses, Sandy Ribes (URP 2496, Université de Paris, France) for her assistance regarding mouse genotyping and immunohistochemistry analysis, Thomas Guilbert (IMAG'IC, Institut Cochin, Paris, France) for his precious help in SHG, Dr Gael Rochefort (SATT Lutech / Sorbonne University Alliance, Paris, France) for his scientific input.

\section{Data availability}

All the data are available upon request. Setrusumab (BPS804) was provided by Mereo Biopharma (London, UK) through a Material transfer agreement (MTA). 


\section{References}

[1] Roberts SJ, Ke HZ. Anabolic Strategies to Augment Bone Fracture Healing. Current osteoporosis reports 2018;16:289-98.

[2] Delgado-Calle J, Sato AY, Bellido T. Role and mechanism of action of sclerostin in bone. Bone 2017;96:29-37.

[3] Poole KE, van Bezooijen RL, Loveridge N, Hamersma H, Papapoulos SE, Löwik $\mathrm{CW}$, Reeve J. Sclerostin is a delayed secreted product of osteocytes that inhibits bone formation. FASEB journal : official publication of the Federation of American Societies for Experimental Biology 2005;19:1842-4.

[4] Lin C, Jiang X, Dai Z, Guo X, Weng T, Wang J, Li Y, Feng G, Gao X, He L. Sclerostin mediates bone response to mechanical unloading through antagonizing Wnt/beta-catenin signaling. Journal of bone and mineral research : the official journal of the American Society for Bone and Mineral Research 2009;24:1651-61.

[5] Li X, Zhang Y, Kang H, Liu W, Liu P, Zhang J, Harris SE, Wu D. Sclerostin binds to LRP5/6 and antagonizes canonical Wnt signaling. The Journal of biological chemistry 2005;280:19883-7.

[6] Baron R, Kneissel M. WNT signaling in bone homeostasis and disease: from human mutations to treatments. Nature medicine 2013;19:179-92.

[7] Compton JT, Lee FY. A review of osteocyte function and the emerging importance of sclerostin. The Journal of bone and joint surgery American volume 2014;96:1659-68.

[8] Liu M, Kurimoto P, Zhang J, Niu QT, Stolina M, Dechow PC, Feng JQ, Hesterman J, Silva MD, Ominsky MS, Richards WG, Ke H, Kostenuik PJ. Sclerostin and DKK1 Inhibition Preserves and Augments Alveolar Bone Volume and Architecture in Rats with Alveolar Bone Loss. Journal of dental research 2018;97:1031-8.

[9] Albiol L, Büttner A, Pflanz D, Mikolajewicz N, Birkhold Al, Kramer I, Kneissel M, Duda GN, Checa S, Willie BM. Effects of Long-Term Sclerostin Deficiency on Trabecular Bone Mass and Adaption to Limb Loading Differ in Male and Female Mice. Calcified tissue international 2020;106:415-30.

[10] Collignon AM, Amri N, Lesieur J, Sadoine J, Ribes S, Menashi S, Simon S, Berdal A, Rochefort GY, Chaussain C, Gaucher C. Sclerostin Deficiency Promotes Reparative Dentinogenesis. Journal of dental research 2017;96:815-21.

[11] Li C, Ominsky MS, Tan HL, Barrero M, Niu QT, Asuncion FJ, Lee E, Liu M, Simonet WS, Paszty C, Ke HZ. Increased callus mass and enhanced strength during fracture healing in mice lacking the sclerostin gene. Bone 2011;49:1178-85. [12] Fairfield H, Falank C, Harris E, Demambro V, McDonald M, Pettitt JA, Mohanty ST, Croucher P, Kramer I, Kneissel M, Rosen CJ, Reagan MR. The skeletal cellderived molecule sclerostin drives bone marrow adipogenesis. Journal of cellular physiology 2018;233:1156-67. 
[13] Stegen S, Stockmans I, Moermans K, Thienpont B, Maxwell PH, Carmeliet P, Carmeliet $\mathrm{G}$. Osteocytic oxygen sensing controls bone mass through epigenetic regulation of sclerostin. Nature communications 2018;9:2557.

[14] Miyauchi A, Dinavahi RV, Crittenden DB, Yang W, Maddox JC, Hamaya E, Nakamura Y, Libanati C, Grauer A, Shimauchi J. Increased bone mineral density for 1 year of romosozumab, vs placebo, followed by 2 years of denosumab in the Japanese subgroup of the pivotal FRAME trial and extension. Archives of osteoporosis 2019;14:59.

[15] Lewiecki EM, Dinavahi RV, Lazaretti-Castro M, Ebeling PR, Adachi JD, Miyauchi A, Gielen E, Milmont CE, Libanati C, Grauer A. One Year of Romosozumab Followed by Two Years of Denosumab Maintains Fracture Risk Reductions: Results of the FRAME Extension Study. Journal of bone and mineral research : the official journal of the American Society for Bone and Mineral Research 2019;34:419-28.

[16] McClung MR. Emerging Therapies for Osteoporosis. Endocrinology and metabolism (Seoul, Korea) 2015;30:429-35.

[17] McClung MR, Grauer A, Boonen S, Bolognese MA, Brown JP, Diez-Perez A, Langdahl BL, Reginster JY, Zanchetta JR, Wasserman SM, Katz L, Maddox J, Yang YC, Libanati C, Bone HG. Romosozumab in postmenopausal women with low bone mineral density. The New England journal of medicine 2014;370:412-20.

[18] Recknor CP, Recker RR, Benson CT, Robins DA, Chiang AY, Alam J, Hu L, Matsumoto T, Sowa H, Sloan JH, Konrad RJ, Mitlak BH, Sipos AA. The Effect of Discontinuing Treatment With Blosozumab: Follow-up Results of a Phase 2 Randomized Clinical Trial in Postmenopausal Women With Low Bone Mineral Density. Journal of bone and mineral research : the official journal of the American Society for Bone and Mineral Research 2015;30:1717-25.

[19] Ralston SH, Gaston MS. Management of Osteogenesis Imperfecta. Frontiers in endocrinology 2019;10:924.

[20] Glorieux FH, Devogelaer JP, Durigova M, Goemaere S, Hemsley S, Jakob F, Junker U, Ruckle J, Seefried L, Winkle PJ. BPS804 Anti-Sclerostin Antibody in Adults With Moderate Osteogenesis Imperfecta: Results of a Randomized Phase 2a Trial. Journal of bone and mineral research : the official journal of the American Society for Bone and Mineral Research 2017;32:1496-504.

[21] Fabre S, Funck-Brentano T, Cohen-Solal M. Anti-Sclerostin Antibodies in Osteoporosis and Other Bone Diseases. J Clin Med 2020;9.

[22] Larsson S. Anti-sclerostin - is there an indication? Injury 2016;47 Suppl 1:S31-5. [23] Cui L, Cheng H, Song C, Li C, Simonet WS, Ke HZ, Li G. Time-dependent effects of sclerostin antibody on a mouse fracture healing model. Journal of musculoskeletal \& neuronal interactions 2013;13:178-84.

[24] Suen PK, He YX, Chow DH, Huang L, Li C, Ke HZ, Ominsky MS, Qin L. Sclerostin monoclonal antibody enhanced bone fracture healing in an open osteotomy model in rats. Journal of orthopaedic research : official publication of the Orthopaedic Research Society 2014;32:997-1005.

[25] Virk MS, Alaee F, Tang H, Ominsky MS, Ke HZ, Lieberman JR. Systemic administration of sclerostin antibody enhances bone repair in a critical-sized femoral defect in a rat model. The Journal of bone and joint surgery American volume 2013;95:694-701.

[26] Alzahrani MM, Rauch F, Hamdy RC. Does Sclerostin Depletion Stimulate Fracture Healing in a Mouse Model? Clinical orthopaedics and related research 2016;474:1294-302. 
[27] Yee CS, Xie L, Hatsell S, Hum N, Murugesh D, Economides AN, Loots GG, Collette NM. Sclerostin antibody treatment improves fracture outcomes in a Type I diabetic mouse model. Bone 2016;82:122-34.

[28] Yao Q, Ni J, Hou Y, Ding L, Zhang L, Jiang H. Expression of sclerostin scFv and the effect of sclerostin scFv on healing of osteoporotic femur fracture in rats. Cell biochemistry and biophysics 2014;69:229-35.

[29] Yao W, Dai W, Jiang L, Lay EY, Zhong Z, Ritchie RO, Li X, Ke H, Lane NE. Sclerostin-antibody treatment of glucocorticoid-induced osteoporosis maintained bone mass and strength. Osteoporosis international : a journal established as result of cooperation between the European Foundation for Osteoporosis and the National Osteoporosis Foundation of the USA 2016;27:283-94.

[30] Agholme F, Li X, Isaksson H, Ke HZ, Aspenberg P. Sclerostin antibody treatment enhances metaphyseal bone healing in rats. Journal of bone and mineral research : the official journal of the American Society for Bone and Mineral Research 2010;25:2412-8.

[31] Hu B, Li Y, Wang M, Zhu Y, Zhou Y, Sui B, Tan Y, Ning Y, Wang J, He J, Yang $\mathrm{C}$, Zou D. Functional reconstruction of critical-sized load-bearing bone defects using a Sclerostin-targeting miR-210-3p-based construct to enhance osteogenic activity. Acta Biomater 2018;76:275-82.

[32] Yorukoglu AC, Kiter AE, Akkaya S, Satiroglu-Tufan NL, Tufan AC. A Concise Review on the Use of Mesenchymal Stem Cells in Cell Sheet-Based Tissue Engineering with Special Emphasis on Bone Tissue Regeneration. Stem cells international 2017;2017:2374161.

[33] La Noce M, Paino F, Spina A, Naddeo P, Montella R, Desiderio V, De Rosa A, Papaccio G, Tirino V, Laino L. Dental pulp stem cells: state of the art and suggestions for a true translation of research into therapy. Journal of dentistry 2014;42:761-8.

[34] Tatullo M, Marrelli M, Shakesheff KM, White LJ. Dental pulp stem cells: function, isolation and applications in regenerative medicine. Journal of tissue engineering and regenerative medicine 2015;9:1205-16.

[35] Kunimatsu R, Nakajima K, Awada T, Tsuka Y, Abe T, Ando K, Hiraki T, Kimura A, Tanimoto K. Comparative characterization of stem cells from human exfoliated deciduous teeth, dental pulp, and bone marrow-derived mesenchymal stem cells. Biochemical and biophysical research communications 2018;501:193-8.

[36] Gronthos S, Mankani M, Brahim J, Robey PG, Shi S. Postnatal human dental pulp stem cells (DPSCs) in vitro and in vivo. Proceedings of the National Academy of Sciences of the United States of America 2000;97:13625-30.

[37] Le Douarin NM, Calloni GW, Dupin E. The stem cells of the neural crest. Cell cycle (Georgetown, Tex) 2008;7:1013-9.

[38] Quarto N, Wan DC, Kwan MD, Panetta NJ, Li S, Longaker MT. Origin matters: differences in embryonic tissue origin and Wnt signaling determine the osteogenic potential and healing capacity of frontal and parietal calvarial bones. Journal of bone and mineral research : the official journal of the American Society for Bone and Mineral Research 2010;25:1680-94.

[39] Chamieh F, Collignon AM, Coyac BR, Lesieur J, Ribes S, Sadoine J, Llorens A, Nicoletti A, Letourneur D, Colombier ML, Nazhat SN, Bouchard P, Chaussain C, Rochefort GY. Accelerated craniofacial bone regeneration through dense collagen gel scaffolds seeded with dental pulp stem cells. Scientific reports 2016;6:38814. 
[40] Behnia A, Haghighat A, Talebi A, Nourbakhsh N, Heidari F. Transplantation of stem cells from human exfoliated deciduous teeth for bone regeneration in the dog mandibular defect. World journal of stem cells 2014;6:505-10.

[41] Leyendecker Junior A, Gomes Pinheiro CC, Lazzaretti Fernandes T, Franco Bueno D. The use of human dental pulp stem cells for in vivo bone tissue engineering: A systematic review. Journal of tissue engineering 2018;9:2041731417752766.

[42] Ramamoorthi M, Bakkar M, Jordan J, Tran SD. Osteogenic Potential of Dental Mesenchymal Stem Cells in Preclinical Studies: A Systematic Review Using Modified ARRIVE and CONSORT Guidelines. Stem cells international 2015;2015:378368.

[43] Novais A, Lesieur J, Sadoine J, Slimani L, Baroukh B, Saubaméa B, Schmitt A, Vital S, Poliard A, Hélary C, Rochefort GY, Chaussain C, Gorin C. Priming Dental Pulp Stem Cells from Human Exfoliated Deciduous Teeth with Fibroblast Growth Factor-2 Enhances Mineralization Within Tissue-Engineered Constructs Implanted in Craniofacial Bone Defects. Stem cells translational medicine 2019;8:844-57. [44] Collignon AM, Castillo-Dali G, Gomez E, Guilbert T, Lesieur J, Nicoletti A, Acuna-Mendoza S, Letourneur D, Chaussain C, Rochefort GY, Poliard A. Mouse Wnt1-CRE-Rosa(Tomato) Dental Pulp Stem Cells Directly Contribute to the Calvarial Bone Regeneration Process. Stem cells (Dayton, Ohio) 2019;37:701-11. [45] Ho-Shui-Ling A, Bolander J, Rustom LE, Johnson AW, Luyten FP, Picart C. Bone regeneration strategies: Engineered scaffolds, bioactive molecules and stem cells current stage and future perspectives. Biomaterials 2018;180:143-62. [46] Bose S, Li S, Mele E, Silberschmidt VV. Dry vs. wet: Properties and performance of collagen films. Part II. Cyclic and time-dependent behaviours. Journal of the mechanical behavior of biomedical materials 2020;112:104040. [47] Qu HW, Fu HY, Han ZY, Sun Y. Biomaterials for bone tissue engineering scaffolds: a review. Rsc Adv 2019;9:26252-62.

[48] Cen L, Liu W, Cui L, Zhang W, Cao Y. Collagen tissue engineering: development of novel biomaterials and applications. Pediatric research 2008;63:4926.

[49] Ferreira AM, Gentile P, Chiono V, Ciardelli G. Collagen for bone tissue regeneration. Acta Biomater 2012;8:3191-200.

[50] Koons GL, Diba M, Mikos AG. Materials design for bone-tissue engineering. Nat Rev Mater 2020;5:584-603.

[51] Ajalloueian F, Nikogeorgos N, Ajalloueian A, Fossum M, Lee S, Chronakis IS. Compressed collagen constructs with optimized mechanical properties and cell interactions for tissue engineering applications. International journal of biological macromolecules 2018;108:158-66.

[52] Coyac BR, Chicatun F, Hoac B, Nelea V, Chaussain C, Nazhat SN, McKee MD. Mineralization of dense collagen hydrogel scaffolds by human pulp cells. Journal of dental research 2013;92:648-54.

[53] Chicatun F, Pedraza CE, Ghezzi CE, Marelli B, Kaartinen MT, McKee MD, Nazhat SN. Osteoid-mimicking dense collagen/chitosan hybrid gels.

Biomacromolecules 2011;12:2946-56.

[54] Guille MMG, Helary C, Vigier S, Nassif N. Dense fibrillar collagen matrices for tissue repair. Soft Matter 2010;6:4963-7.

[55] Bitar M, Salih V, Brown RA, Nazhat SN. Effect of multiple unconfined compression on cellular dense collagen scaffolds for bone tissue engineering. Journal of materials science Materials in medicine 2007;18:237-44. 
[56] Buxton PG, Bitar M, Gellynck K, Parkar M, Brown RA, Young AM, Knowles JC, rescues the apoptotic response to MMP inhibition. Bone 2008;43:377-85.

[57] Gao C, Harvey EJ, Chua M, Chen BP, Jiang F, Liu Y, Li A, Wang H, Henderson JE. MSC-seeded dense collagen scaffolds with a bolus dose of VEGF promote healing of large bone defects. European cells \& materials 2013;26:195-207; discussion

[58] Griffanti G, Nazhat SN. Dense fibrillar collagen-based hydrogels as functional osteoid-mimicking scaffolds. Int Mater Rev 2020;65:502-21.

[59] Leach DG, Young S, Hartgerink JD. Advances in immunotherapy delivery from implantable and injectable biomaterials. Acta Biomater 2019;88:15-31.

[60] Wang C, Ye Y, Hu Q, Bellotti A, Gu Z. Tailoring Biomaterials for Cancer Immunotherapy: Emerging Trends and Future Outlook. Advanced materials 2017;29. [61] Weber JS, Mule JJ. Cancer immunotherapy meets biomaterials. Nature biotechnology 2015;33:44-5.

[62] Roschger A, Roschger P, Keplingter P, Klaushofer K, Abdullah S, Kneissel M, Rauch F. Effect of sclerostin antibody treatment in a mouse model of severe osteogenesis imperfecta. Bone 2014;66:182-8.

[63] Abou Neel EA, Bozec L, Knowles JC, Syed O, Mudera V, Day R, Hyun JK. Collagen--emerging collagen based therapies hit the patient. Advanced drug delivery reviews 2013;65:429-56.

[64] Brown RA, Wiseman M, Chuo CB, Cheema U, Nazhat SN. Ultrarapid engineering of biomimetic materials and tissues: Fabrication of nano- and microstructures by plastic compression. Adv Funct Mater 2005;15:1762-70. [65] Rajan N, Habermehl J, Cote MF, Doillon CJ, Mantovani D. Preparation of readyto-use, storable and reconstituted type I collagen from rat tail tendon for tissue engineering applications. Nature protocols 2006;1:2753-8.

[66] Pedraza CE, Marelli B, Chicatun F, McKee MD, Nazhat SN. An in vitro assessment of a cell-containing collagenous extracellular matrix-like scaffold for bone tissue engineering. Tissue engineering Part A 2010;16:781-93.

[67] Spicer PP, Kretlow JD, Young S, Jansen JA, Kasper FK, Mikos AG. Evaluation of bone regeneration using the rat critical size calvarial defect. Nature protocols 2012;7:1918-29.

[68] Rosset A, Spadola L, Ratib O. OsiriX: an open-source software for navigating in multidimensional DICOM images. Journal of digital imaging 2004;17:205-16.

[69] Bouxsein ML, Boyd SK, Christiansen BA, Guldberg RE, Jepsen KJ, Muller R. Guidelines for assessment of bone microstructure in rodents using micro-computed tomography. Journal of bone and mineral research : the official journal of the American Society for Bone and Mineral Research 2010;25:1468-86.

[70] Lafont J, Baroukh B, Berdal A, Colombier ML, Barritault D, Caruelle JP, Saffar JL. RGTA11, a new healing agent, triggers developmental events during healing of craniotomy defects in adult rats. Growth factors 1998;16:23-38.

[71] Schindelin J, Arganda-Carreras I, Frise E, Kaynig V, Longair M, Pietzsch T, Preibisch S, Rueden C, Saalfeld S, Schmid B, Tinevez JY, White DJ, Hartenstein V, Eliceiri K, Tomancak P, Cardona A. Fiji: an open-source platform for biological-image analysis. Nature methods 2012;9:676-82.

[72] Guilbert T, Odin C, Le Grand Y, Gailhouste L, Turlin B, Ezan F, Desille Y, Baffet G, Guyader D. A robust collagen scoring method for human liver fibrosis by second harmonic microscopy. Optics express 2010;18:25794-807. 
[73] Collignon AM, Lesieur J, Anizan N, Azzouna RB, Poliard A, Gorin C, Letourneur imaging with (64)Cu-NODAGA-RGD is predictive of bone critical defect repair. Acta Biomater 2018;82:111-21.

[74] McGee-Lawrence ME, Ryan ZC, Carpio LR, Kakar S, Westendorf JJ, Kumar R. Sclerostin deficient mice rapidly heal bone defects by activating $\beta$-catenin and increasing intramembranous ossification. Biochemical and biophysical research communications 2013;441:886-90.

[75] Pathak JL, Bravenboer N, Klein-Nulend J. The Osteocyte as the New Discovery of Therapeutic Options in Rare Bone Diseases. Frontiers in endocrinology 2020;11:405.

[76] Russow G, Jahn D, Appelt J, Mardian S, Tsitsilonis S, Keller J. Anabolic Therapies in Osteoporosis and Bone Regeneration. International journal of molecular sciences 2018;20.

[77] Santagati F, Rijli FM. Cranial neural crest and the building of the vertebrate head. Nat Rev Neurosci 2003;4:806-18.

[78] Senarath-Yapa K, Li S, Meyer NP, Longaker MT, Quarto N. Integration of multiple signaling pathways determines differences in the osteogenic potential and tissue regeneration of neural crest-derived and mesoderm-derived calvarial bones. International journal of molecular sciences 2013;14:5978-97.

[79] Bitar M, Brown RA, Salih V, Kidane AG, Knowles JC, Nazhat SN. Effect of cell density on osteoblastic differentiation and matrix degradation of biomimetic dense collagen scaffolds. Biomacromolecules 2008;9:129-35.

[80] Kwan MD, Quarto N, Gupta DM, Slater BJ, Wan DC, Longaker MT. Differential expression of sclerostin in adult and juvenile mouse calvariae. Plastic and reconstructive surgery 2011;127:595-602.

[81] Kang KS, Lastfogel J, Ackerman LL, Jea A, Robling AG, Tholpady SS. Loss of mechanosensitive sclerostin may accelerate cranial bone growth and regeneration. Journal of neurosurgery 2018;129:1085-91.

[82] Colditz J, Thiele S, Baschant U, Niehrs C, Bonewald LF, Hofbauer LC, Rauner M. Postnatal Skeletal Deletion of Dickkopf-1 Increases Bone Formation and Bone Volume in Male and Female Mice, Despite Increased Sclerostin Expression. Journal of bone and mineral research : the official journal of the American Society for Bone and Mineral Research 2018;33:1698-707.

[83] Schupbach D, Comeau-Gauthier M, Harvey E, Merle G. Wnt modulation in bone healing. Bone 2020;138:115491.

[84] Li M, Li S, Liu J, Cui X, Zhang S, Zhou J, Wang X, Yao Q. Sustained-release of sclerostin single-chain antibody fragments using poly(lactic-co-glycolic acid) microspheres for osteoporotic fracture repair. Journal of biomedical materials research Part A 2019;107:1832-40.

[85] Iolascon G, Moretti A, Toro G, Gimigliano F, Liguori S, Paoletta M. Pharmacological Therapy of Osteoporosis: What's New? Clinical interventions in aging 2020;15:485-91.

[86] Canalis E. MANAGEMENT OF ENDOCRINE DISEASE: Novel anabolic treatments for osteoporosis. European journal of endocrinology 2018;178:R33-R44. [87] Saag KG, Petersen J, Brandi ML, Karaplis AC, Lorentzon M, Thomas T, Maddox J, Fan M, Meisner PD, Grauer A. Romosozumab or Alendronate for Fracture Prevention in Women with Osteoporosis. The New England journal of medicine 2017;377:1417-27. 
[88] Hadaya D, Gkouveris I, Soundia A, Bezouglaia O, Boyce RW, Stolina M, Dwyer Antibody Do Not Induce Osteonecrosis of the Jaw (ONJ) in Rats with Experimental Periodontitis. Journal of bone and mineral research : the official journal of the American Society for Bone and Mineral Research 2019;34:171-81. [89] Ominsky MS, Niu QT, Li C, Li X, Ke HZ. Tissue-level mechanisms responsible for the increase in bone formation and bone volume by sclerostin antibody. Journal of bone and mineral research : the official journal of the American Society for Bone and Mineral Research 2014;29:1424-30.

[90] Appelman-Dijkstra NM, Papapoulos SE. Sclerostin Inhibition in the Management of Osteoporosis. Calcified tissue international 2016;98:370-80.

[91] Ren Y, Han X, Ho SP, Harris SE, Cao Z, Economides AN, Qin C, Ke H, Liu M, Feng JQ. Removal of SOST or blocking its product sclerostin rescues defects in the periodontitis mouse model. FASEB journal : official publication of the Federation of American Societies for Experimental Biology 2015;29:2702-11.

[92] Balani DH, Trinh S, Xu M, Kronenberg HM. Sclerostin Antibody Administration Increases the Numbers of Sox9creER+ Skeletal Precursors and Their Progeny. Journal of bone and mineral research : the official journal of the American Society for Bone and Mineral Research 2021;36:757-67.

[93] Glass DA, 2nd, Bialek P, Ahn JD, Starbuck M, Patel MS, Clevers H, Taketo MM, Long F, McMahon AP, Lang RA, Karsenty G. Canonical Wnt signaling in differentiated osteoblasts controls osteoclast differentiation. Dev Cell 2005;8:751-64. [94] Farr JN, Khosla S. Skeletal changes through the lifespan--from growth to senescence. Nature reviews Endocrinology 2015;11:513-21.

[95] Falland-Cheung L, Waddell JN, Chun Li K, Tong D, Brunton P. Investigation of the elastic modulus, tensile and flexural strength of five skull simulant materials for impact testing of a forensic skin/skull/brain model. Journal of the mechanical behavior of biomedical materials 2017;68:303-7.

[96] Wang D, Gilbert JR, Zhang X, Zhao B, Ker DFE, Cooper GM. Calvarial Versus Long Bone: Implications for Tailoring Skeletal Tissue Engineering. Tissue engineering Part B, Reviews 2020;26:46-63. 
1

2
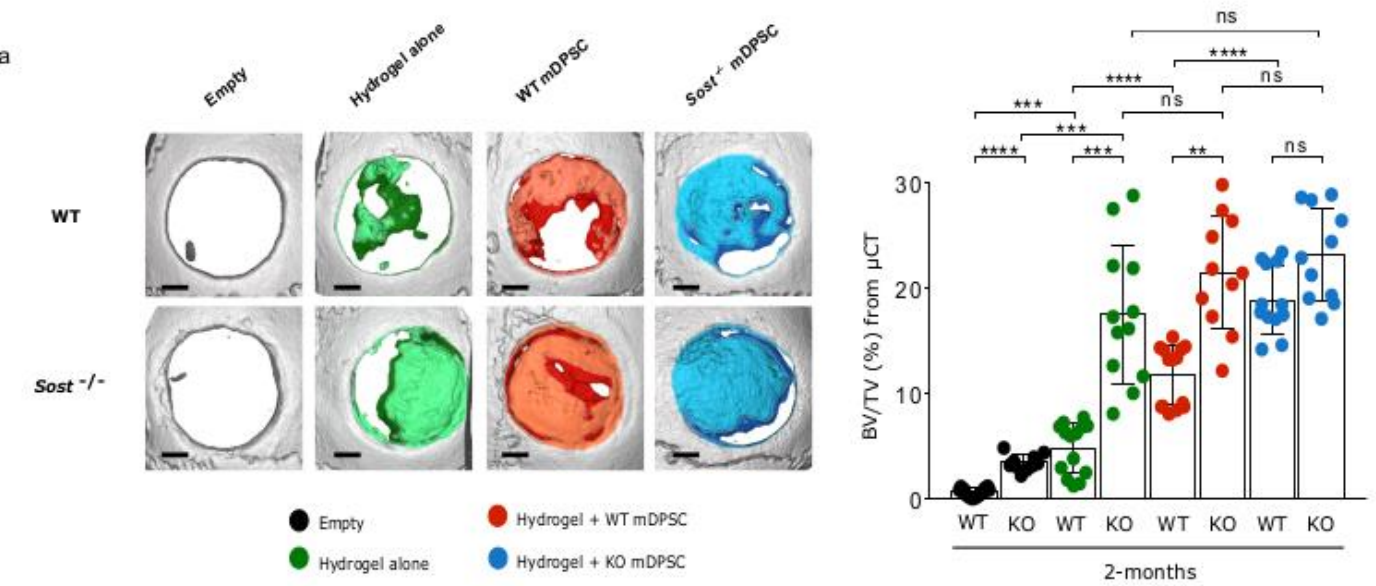

b
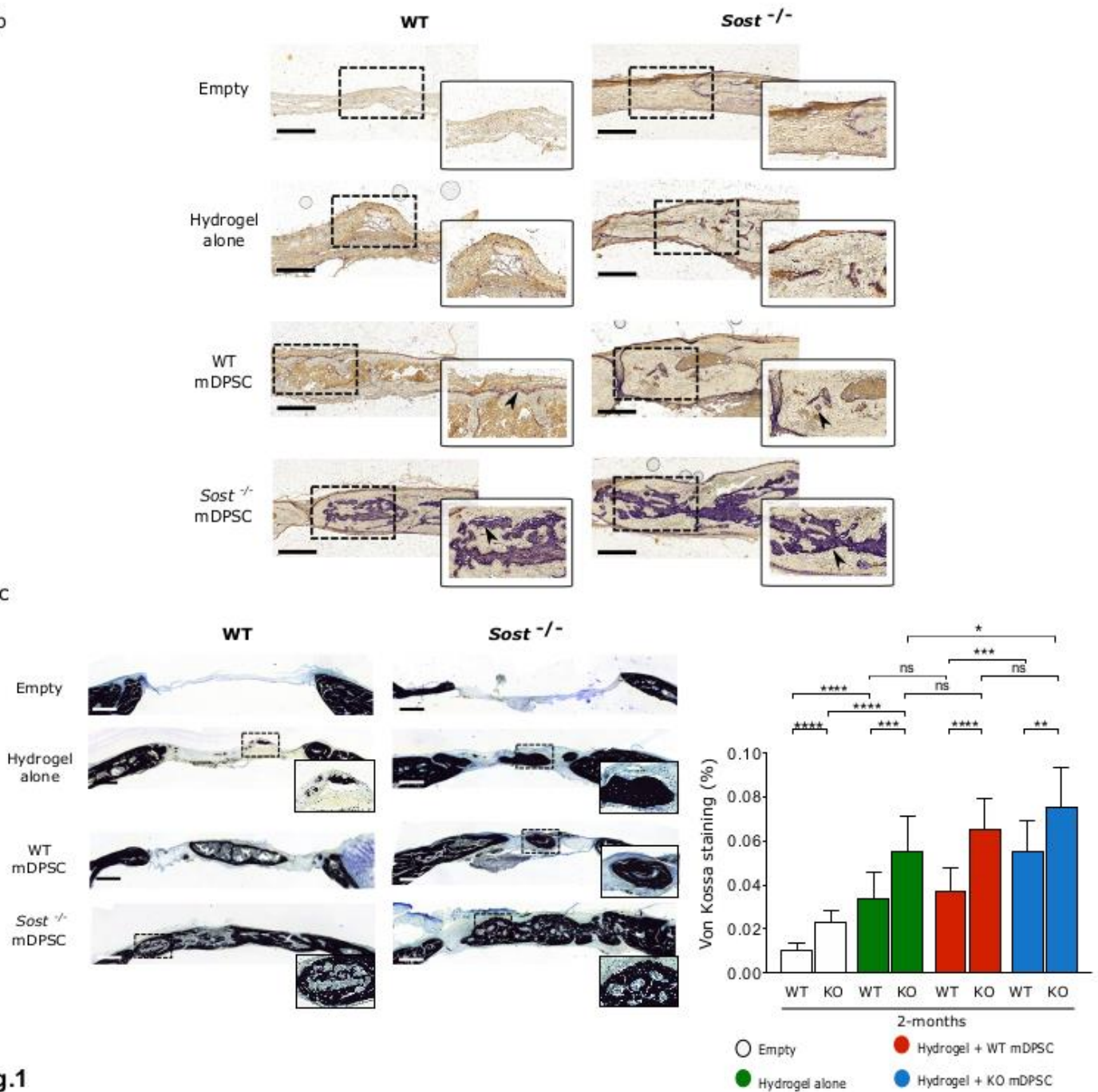

Fig.1 
WT

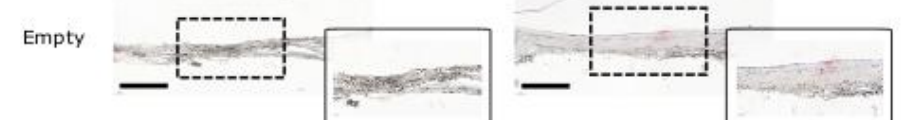

Hydrogel
alone
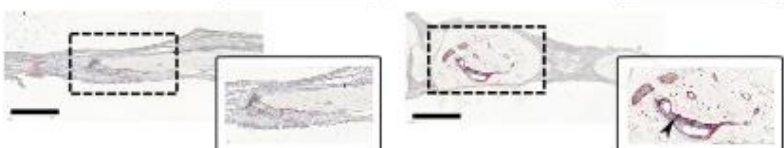

WT

mDPSC

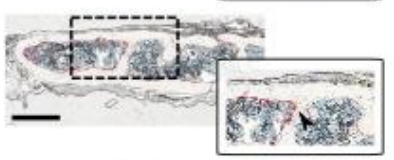

Sost
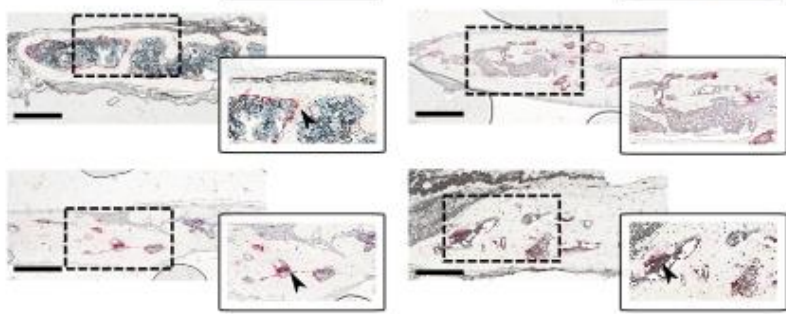

b
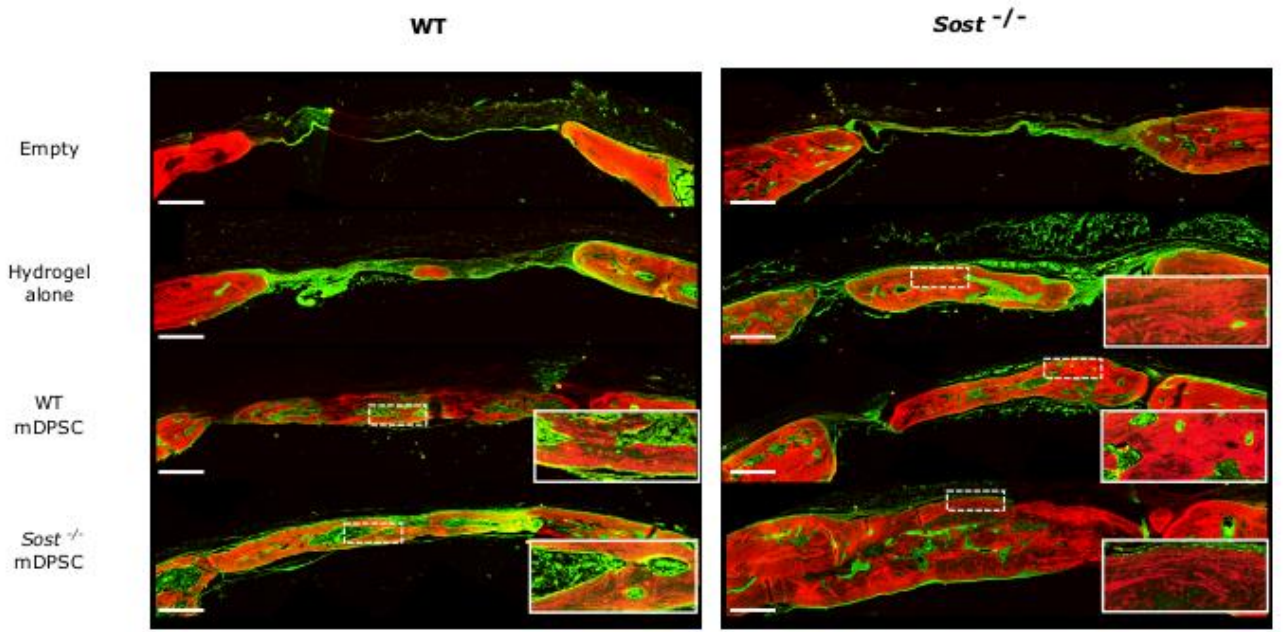

C

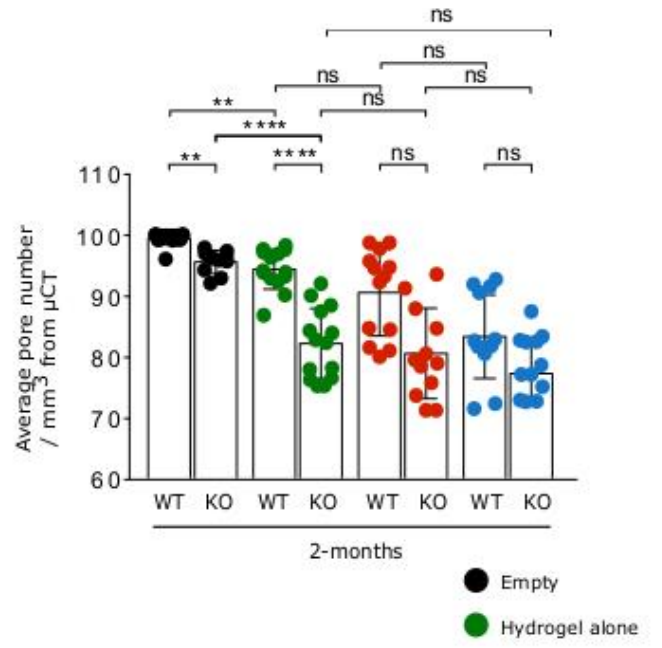

Fig. 2

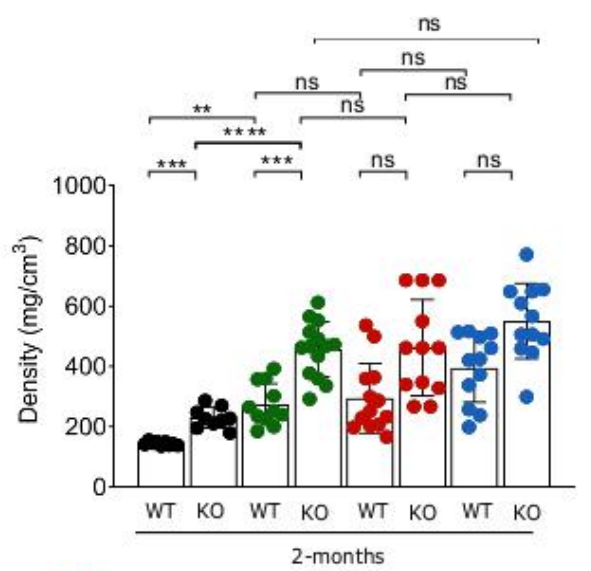

Hydrogel + WT mDPSC

Hydrogel + KO mDPSC

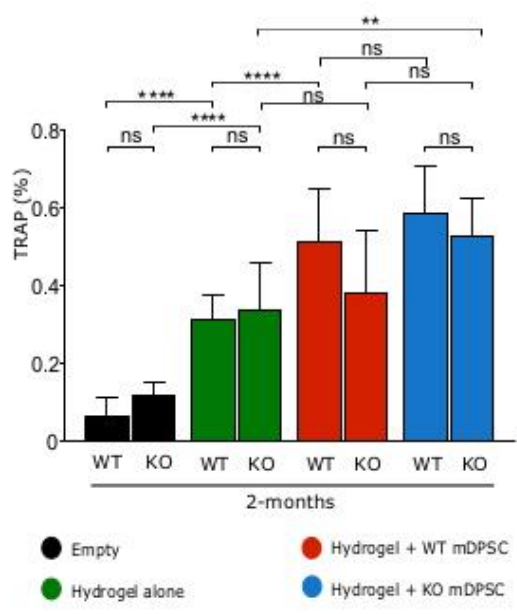

Sost $-1-$ 
a

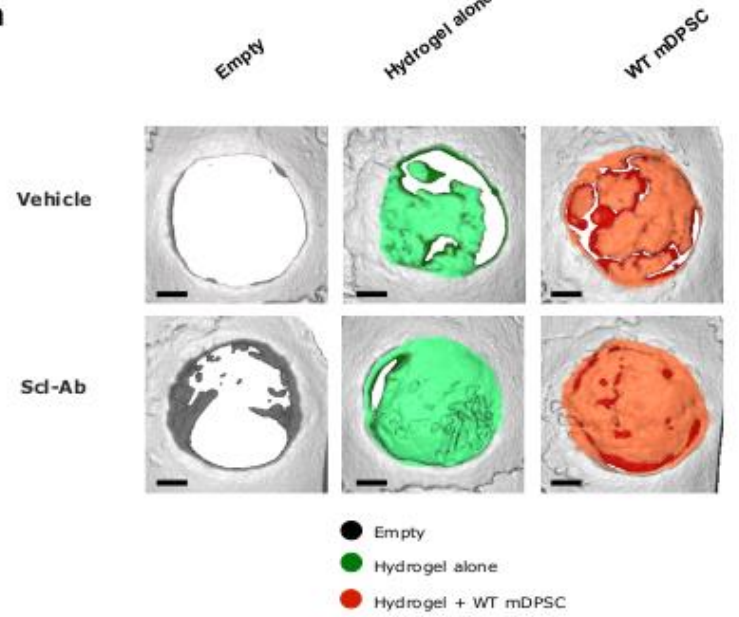

b

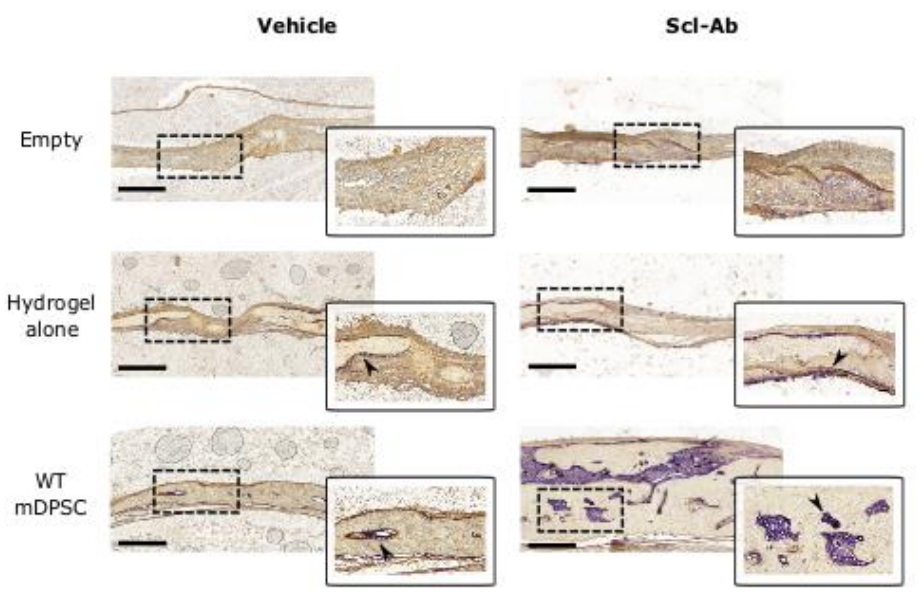

C

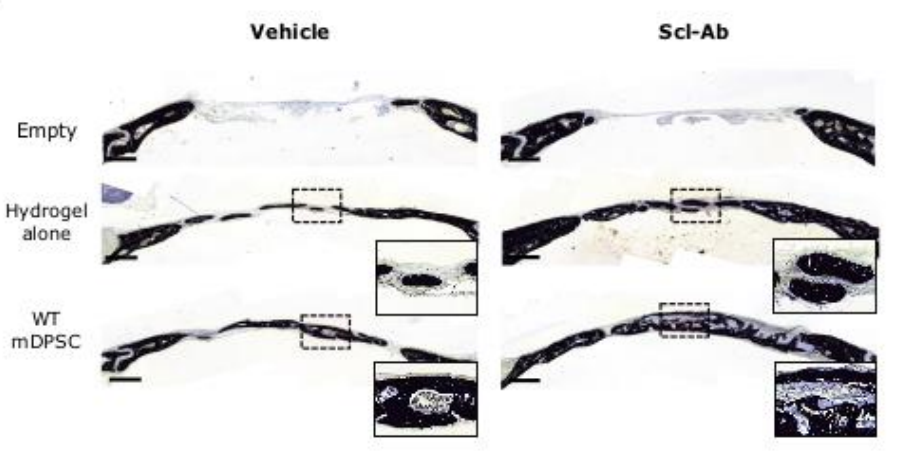

Fig. 3

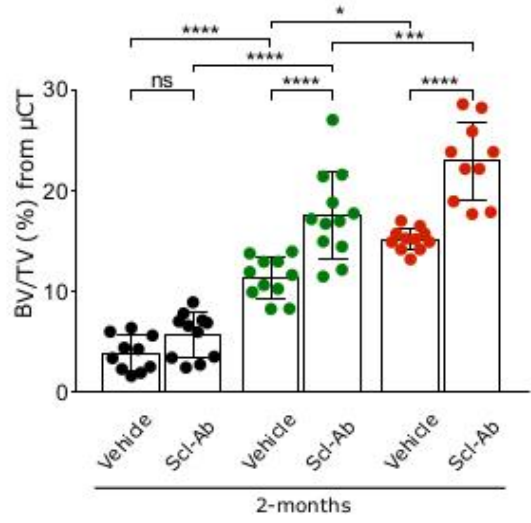

Scl-Ab

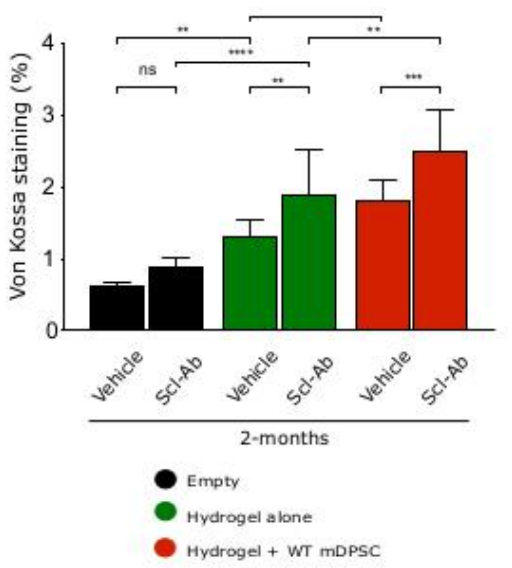


a
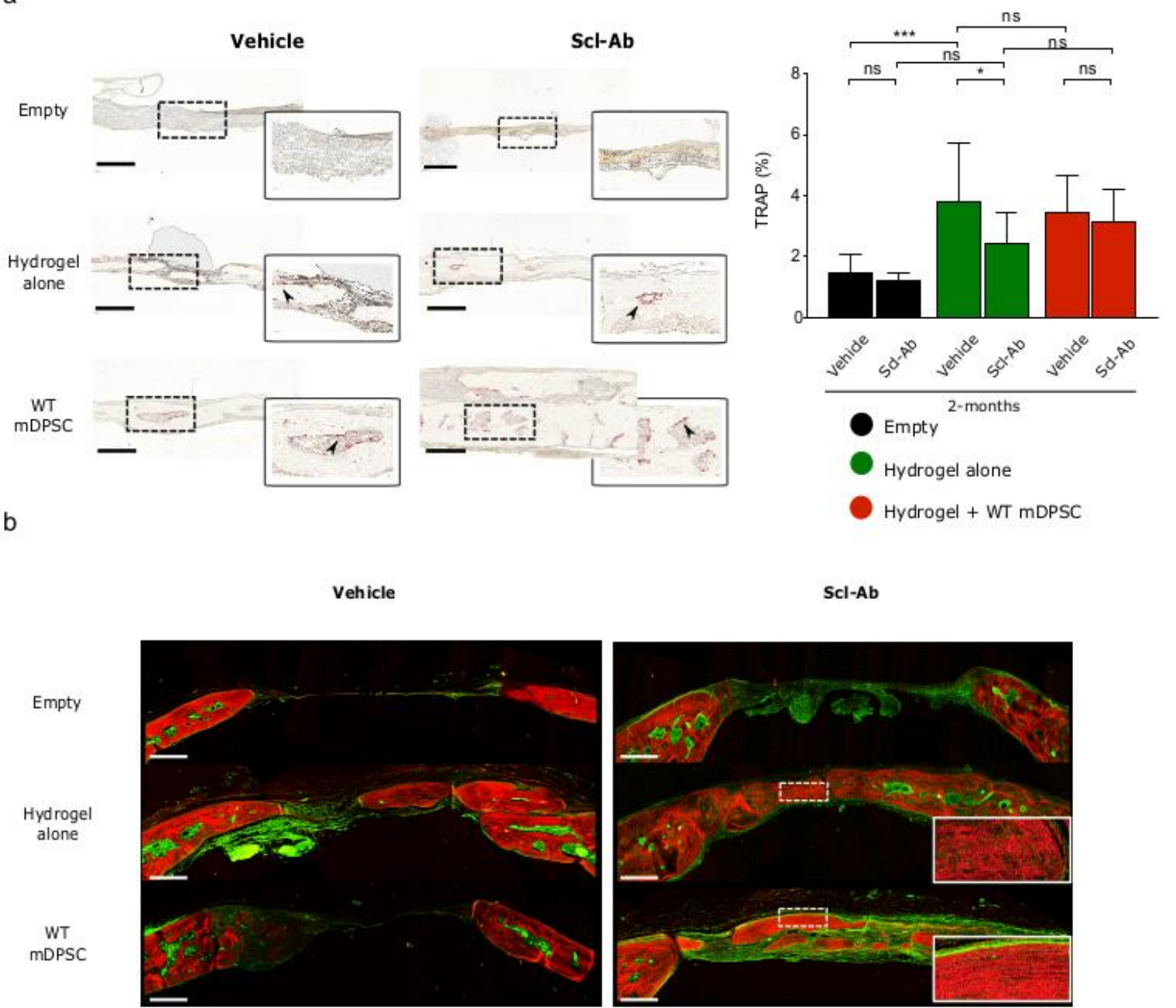

C

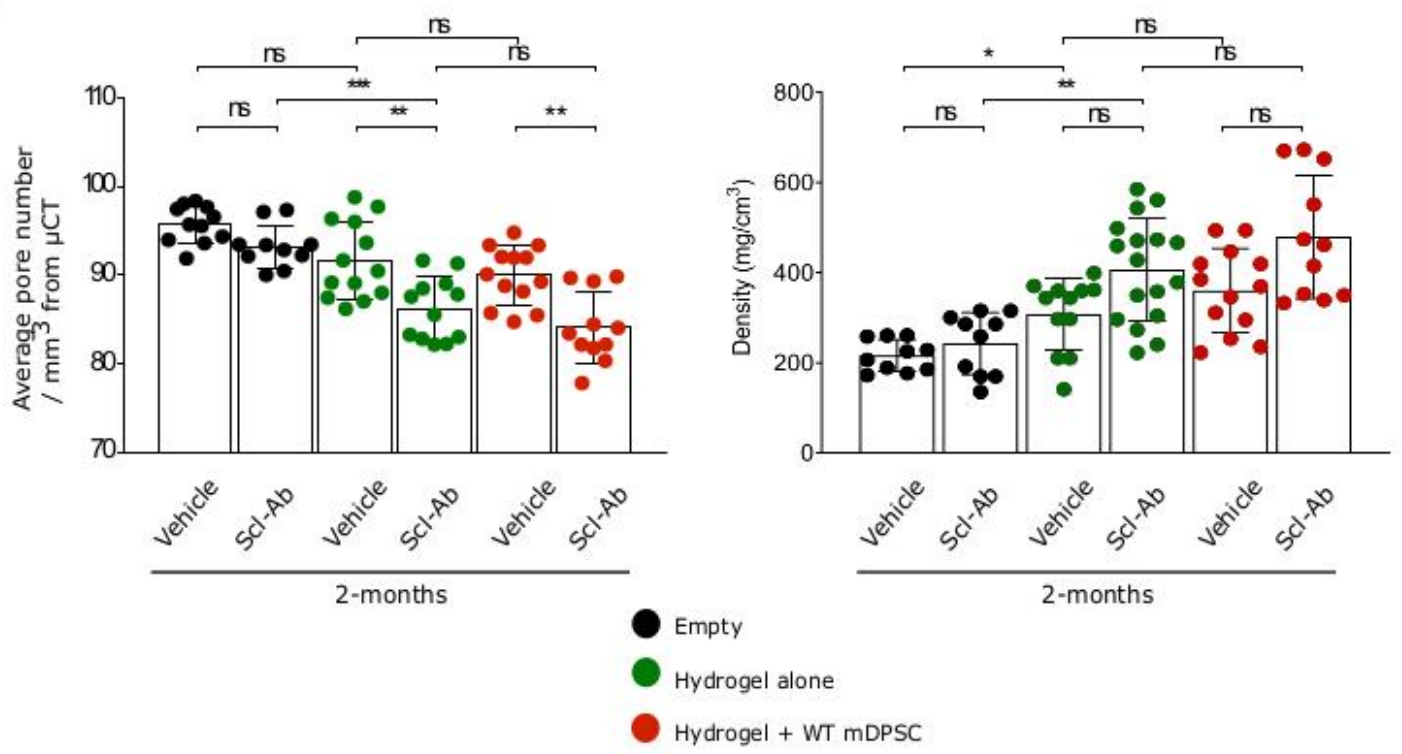




\section{Figure captions}

\section{Figure 1: Bone formation within the defect at two months.}

a) Representative three dimensional images of bone defects created in WT and Sost KO mice in four conditions: defect left empty, defect filled with acellular hydrogel, hydrogel seeded WT mDPSC and hydrogel seeded Sost KO mDPSC. Black color represents the empty defect, green color represents newly formed bone in a defect filled with acellular hydrogel, red color represents newly formed bone in a defect filled with a hydrogel seeded with WT mDPSC and blue color represents newly formed bone in a defect filled with a hydrogel seeded with Sost KO mDPSC. Newly formed bone volumetric fraction is expressed as a percentage of volume (BV/TV) on the total area of the defect from micro-CT analysis. Data showed that Sost KO mice presented a significantly higher BV/TV compared to their WT counterparts and that WT mice treated with Sost KO mDPSC-seeded hydrogels displayed a similar BV/TV compared to Sost KO mice.

b) Staining of osteoblastic-associated alkaline phosphatase (ALP) activity was investigated to assess bone formation by osteoblasts. ALP activity, in purple, was strong in WT mice treated with Sost KO cells and in Sost KO mice, especially those treated with Sost KO cells. Inset detail shows the area of interest with ALP signals indicated by arrows at higher magnification (x 40).

c) Mineral formation in calvarial bone defects revealed by Von Kossa staining. Inset detail displays the area of interest at higher magnification (x 40). Quantitative analysis of Von Kossa staining in \% have been performed in four conditions: defect left empty, defect filled with acellular hydrogel, hydrogel seeded WT mDPSC and hydrogel seeded Sost KO mDPSC. Black color represents the empty defect, green color represents newly formed bone in a defect filled with acellular hydrogel, red color 
represents newly formed bone in a defect filled with a hydrogel seeded with WT mDPSC and blue color represents newly formed bone in a defect filled with a hydrogel seeded with Sost KO mDPSC. Results showed that mineral formation was significantly higher in WT and Sost KO mice treated with Sost KO mDPSC.

Scale bars: a) $1 \mathrm{~mm}$, b) $250 \mu \mathrm{m}$ c) $400 \mu \mathrm{m}$. Values represent mean \pm SD: ns: not significant; $* P<0.05 ; * * P<0.01, * * * P<0.001$ and $* * * * P<0.0001$ with a Brown-Forsythe and Welch ANOVA test.

Figure 2: Characterization of newly formed bone in WT and Sost KO mice at two months.

a) Staining of osteoclastic tartrate-resistant acid phosphatase (TRAP) activity images on WT and Sost KO mice in defects filled with WT and Sost KO mDPSC. Inset detail displays, at higher magnification (x 40), TRAP signals in rose red indicated by arrows. Quantification of TRAP activity (\%) has been performed: black color represents the empty defect, green color represents newly formed bone in a defect filled with acellular hydrogel, red color represents newly formed bone in a defect filled with a hydrogel seeded with WT mDPSC and blue color represents newly formed bone in a defect filled with a hydrogel seeded with Sost KO mDPSC. Results showed no significant difference between the cellularized scaffold groups at this stage of the repair process.

b) Images from second harmonic generation (SHG) microscopy showed large amount of red-labeled well-organized bundles of collagen fibers within the defects performed in Sost KO mice for all the conditions (acellular hydrogel, hydrogel seeded with WT mDPSC and Sost KO mDPSC) and in WT mice treated with Sost KO cells. Inset detail shows the area of interest at higher magnification (x 40).

c) Quantitative analysis of bone porosity $\left(\mathrm{mm}^{-3}\right)$ and density $\left(\mathrm{mg} / \mathrm{cm}^{3}\right)$ from micro-CT acquisitions showing no improvement of these microarchitecture parameters in the 
cellularized scaffold groups at this stage of the repair process. Black color represents the empty defect, green color represents newly formed bone in a defect filled with acellular hydrogel, red color represents newly formed bone in a defect filled with a hydrogel seeded with WT mDPSC and blue color represents newly formed bone in a defect filled with a hydrogel seeded with Sost KO mDPSC.

Scale bar: a) $250 \mu \mathrm{m}$, b) $500 \mu \mathrm{m}$. Values represent mean \pm SD: ns: not significant; ${ }^{*} P<$ $0.05 ; * * P<0.01, * * * P<0.001$ and $* * * * P<0.0001$ with a Brown-Forsythe and Welch ANOVA test.

\section{Figure 3: Bone formation within calvarial defect in WT mice after Sclerostin antibody} injection at two months.

a) Representative three dimensional images of bone defects created in WT mice either after Scl-AB or vehicle injection, in three conditions: defect left empty, defect filled with acellular hydrogel, defect filled with hydrogel seeded WT mDPSC. Black color represents the empty defect, green color represents newly formed bone in a defect filled with acellular hydrogel and red color represents newly formed bone in a defect filled with a hydrogel seeded with WT mDPSC. Newly formed bone volumetric fraction expressed as a percentage of volume (BV/TV) on the total area of the defect from micro$\mathrm{CT}$ analysis is represented. Micro-CT analysis showed significantly higher BV/TV in animals that received Scl-Ab injection when compared to vehicle in the condition "acellular hydrogel" and "hydrogel seeded with WT mDPSC". In the Scl-Ab treated mice, the addition of cells in the hydrogels significantly enhanced bone formation.

b) Staining of osteoblastic-associated alkaline phosphatase (ALP) activity was investigated to determine whether the Scl-Ab treatment impacted bone formation by osteoblasts. ALP activity, in purple, was strong in mice that received Scl-Ab treatment 
and cellularized hydrogels. Inset detail shows the area of interest with ALP signals indicated by arrows at higher magnification (x 40).

c) Mineral formation in calvarial bone defects revealed by Von Kossa staining. Inset detail displays the area of interest at higher magnification (x 40). Quantitative analysis of Von Kossa staining in \% was performed for the three conditions: defect left empty, defect filled with acellular hydrogel and hydrogel seeded WT mDPSC. Black color represents the empty defect, green color represents newly formed bone in a defect filled with acellular hydrogel and red color represents newly formed bone in a defect filled with a hydrogel seeded with WT mDPSC. Results showed that mineral formation was significantly increased in the conditions "acellular hydrogel" and "hydrogel seeded with WT mDPSC" in mice that received Scl-AB injection compare to vehicle group. Furthermore, in the Scl-Ab treated mice, the addition of cells in the hydrogels significantly enhanced bone formation.

Scale bars: a) $1 \mathrm{~mm}$ b) $250 \mu \mathrm{m}$ c) $400 \mu \mathrm{m}$. Values represent mean \pm SD: ns: not significant; $* P<0.05 ; * * P<0.01, * * * P<0.001$ and $* * * * P<0.0001$ with a Brown-Forsythe and Welch ANOVA test.

\section{Figure 4: Characterization of newly formed bone after Sclerostin antibody injection at}

\section{two months}

a) Staining of osteoclastic tartrate-resistant acid phosphatase (TRAP) activity images in mice treated with Scl-Ab or vehicle. Inset detail shows TRAP signals in rose red indicated by arrows at higher magnification (x 40). Quantification of TRAP activity (\%) was performed for the three conditions: black color represents the empty defect, green color the newly formed bone in a defect filled with acellular hydrogel, and red color the newly formed bone in a defect filled with a hydrogel seeded with WT mDPSC. Results showed significant lower activity for the condition "acellular 
hydrogel" in mice that received Scl-Ab and no difference was found in the cellularized groups.

b) Representative images from second harmonic generation (SHG) microscopy revealed red-stained better-organized collagen fibers in mice treated with the Scl-AB when compared to the vehicle for the conditions "acellular hydrogel" and "hydrogel seeded with WT mDPSC". Inset detail shows the area of interest at higher magnification (x 40).

c) Quantitative analysis of bone porosity $\left(\mathrm{mm}^{-3}\right)$ and density $\left(\mathrm{mg} / \mathrm{cm}^{3}\right)$ from Micro-CT have been performed in three conditions: black color represents the empty defect, green color the newly formed bone in a defect filled with acellular hydrogel, and red color the newly formed bone in a defect filled with a hydrogel seeded with WT mDPSC. Porosity analysis revealed significantly lower porosity in defects performed in animals treated with the Scl-Ab for the conditions "acellular hydrogel" and "hydrogel seeded with WT mDPSC".

Scale bar: a) $250 \mu \mathrm{m}$, b) $500 \mu \mathrm{m}$. Values represent mean \pm SD: ns: not significant; $* P<$ $0.05 ; * * P<0.01, * * * P<0.001$ and $* * * * P<0.0001$ with a Brown-Forsythe and Welch ANOVA test. 